\title{
A FUNÇÃO SOCIAL DO CONTRATO EMPRESARIAL
}

Adelino Borges Ferreira Filho ${ }^{1}$

FERREIRA FILHO, A. B.; A função social do contrato empresarial. Rev. Ciênc. Juríd. Soc. UNIPAR. Umuarama. v. 18, n. 2, p. 201-216, jul./dez. 2015.

RESUMO: As principais transformações do direito privado provocaram a unificação da disciplina jurídica dos negócios jurídicos e da empresa, com o reconhecimento constitucional da importância da iniciativa privada com fundamento nos princípios da ordem econômica. A importância dos contratos empresariais e da empresa contemporânea decorre da dinâmica negocial em uma economia globalizada. O modelo pretérito de contrato empresarial, que visa exclusivamente o lucro, dirige-se para novo perfil, objetivando harmonizar a função econômica, a segurança e a previsibilidade jurídicas em relação ao custo- benefício como fatores de sustentação. A função social do contrato empresarial promove a revisão da função econômica dos pactos para atender os interesses econômicos e os sociais, promovendo a circulação de riquezas e bens, mas limitando a obtenção do lucro como fim exclusivo. A empresa atual, considerada como feixe de relações contratuais e sujeito de direito econômico, mantém a busca do lucro como fim natural, porém, a fim de corrigir distorções de forma a promover a atividade empresarial, contemplando interesses econômicos, jurídicos e sociais. A responsabilidade social da empresa afirma-se, neste contexto, para atender o efeito social que os seus atos possam produzir para além da geração de riquezas. A empresa contemporânea se reorganiza para contemplar fins econômicos e fins sociais, exercendo a atividade empresarial respaldada em princípios e valores, contribuindo para o desenvolvimento e o crescimento econômico e social.

PALAVRAS-CHAVE: Contrato Empresarial; Empresa Contemporânea; Função Social.

\section{INTRODUÇÃO}

A economia contemporânea, vinculada ao modelo capitalista, tem como um de seus alicerces a empresa como responsável importante pela produção e circulação de bens e produtos. Por outro lado, cabe grifar os impactos positivos e negativos causados pela atividade empresarial no ambiente econômico, jurídico

DOI: https://doi.org/10.25110/rcjs.v18i2.2015.5854

${ }^{1}$ PUC-PR CAMPUS CURITIBA. Especialista em Teoria e Prática Empresarial pela PUC-PR Campus Londrina; Advogado inscrito na OAB/PR, e sócio fundador do Escritório Borges Ferreira Advogados Associados; Bacharel em Direito pela PUC-PR Campus Londrina. Autor de Artigos Jurídicos. Membro do CONPEDI, do IBDCivil e do IBCCrim. E-mail: adelino@bflaw.adv.br. 
e social. Se, por um lado, devem ser considerados os fatores exponenciais com os quais a empresa mantém estreita ligação e referentes, principalmente, ao desenvolvimento e crescimento econômicos. De outra parte, devem ser mencionados os impactos decorrentes da atuação negativa da exploração econômica inadequada podendo causar, no polo oposto, disfunção acerca da atividade econômica quando comparada com função social.

As principais transformações do direito privado provocam a unificação da disciplina jurídica dos negócios jurídicos e da empresa com o reconhecimento constitucional da importância da iniciativa privada com fundamento nos princípios da ordem econômica. A autonomia privada com o dirigismo contratual passa por limitações necessárias, sendo que a manifestação da vontade, na perspectiva civil-constitucional, é deslocada para a tutela objetiva da confiança centralizada pelos princípios da dignidade da pessoa humana, da boa-fé objetiva e da função social do contrato.

O modelo pretérito de contrato empresarial visando exclusivamente o lucro dirige-se para novo perfil, objetivando harmonizar a função econômica, a segurança e a previsibilidade jurídicas em relação ao custo benefício como fatores de sustentação. A função social do contrato empresarial promove a revisão da função econômica dos pactos visando atender os interesses econômicos e os sociais, promovendo a circulação de riquezas e bens, mas limitando a obtenção do lucro como fim exclusivo.

A empresa atual, considerada como feixe de relações contratuais e sujeito de direito econômico mantém a busca do lucro como fim natural. Contudo, visa corrigir distorções de forma a promover a atividade empresaria, contemplando interesses econômicos, jurídicos e sociais, se reorganizando para atender fins econômicos e fins sociais, exercendo a atividade empresarial respaldada em princípios e valores, contribuindo para o desenvolvimento e o crescimento econômico e social.

A iniciativa privada reorganizada e de conformidade com os parâmetros socioeconômico, ético e jurídico atua de forma respeitável em espaço próprio e em conjunto com a atuação estatal de forma harmoniosa produzindo resultados positivos em relação a atuação de ambos. Assim sendo, a empresa que atende as necessidades econômicas e sociais se estabelece em um mercado em que circulam fins econômicos em convergência com os fins sociais, a responsabilidade social, fortalecendo as redes de contratos, desenvolvendo ações sociais através de atuação concreta respaldada em princípios e valores, contribuindo para transformação e o crescimento econômico e social.

\section{FUNÇÃO SOCIAL DO CONTRATO EMPRESARIAL}

Pretende-se analisar, na ótica contratual propriamente dita, a função so- 
cial dos contratos empresariais e a implicação deste importante princípio na operabilidade dos contratos empresariais, objetivando equacionar, de forma equilibrada, a função social no que se refere ao dever para com a sociedade-meio em que se realizam e a função econômica própria desta tipicidade negocial.

O contrato empresarial do ponto de vista econômico e jurídico tem por natureza fundamental a função econômica, caracterizada pelo objetivo materializado pelo lucro. Assim sendo, esta modalidade de relação negocial realizada entre empresas ou empresas e indivíduos define-se pela finalidade patrimonial. Por exemplo, quando uma empresa contrata outra para fornecimento de produtos, bens ou serviços, ambas contratam uma troca, na qual a primeira fornece o objeto do contrato e a segunda promove o pagamento de uma certa quantia monetária. A diferença entre o custo do produto, bem ou serviço e o valor de venda é o lucro proveniente da operação. Pois bem, durante muito tempo os contratos empresariais eram realizados sob a influência e orientação deste modelo. Os contratos empresariais não buscavam a satisfação social ou a progressão social e, sim, tão somente, o lucro friamente calculado.

Isto se revela preocupante, pois o contrato é o eixo principal de quase todas as relações empresariais e de consumo, e, muitas vezes, poderia ser lesivo a uma das partes ou à sociedade como um todo. No campo da relação entre sujeitos, o Código de Defesa do Consumidor tutela as relações de consumo, mas, como pode-se tutelar, ou melhor, prevenir o dano à sociedade proveniente das externalidades negativas oriundas dos contratos empresariais?

Para essa resposta, veja-se a função primordial dos contratos:

O único e essencial objetivo do contrato é o de promover a circulação da riqueza, de modo que pressupõe sempre partes diferentes com interesses diversos e opostos. Para harmonizar interesses conflitantes, o contrato se dispõe a ser útil na definição de como aproximá-los e dar-lhes uma saída negocial. Nunca, todavia, o interesse do vendedor será igual ao do comprador, o do mutuante igual ao do mutuário, o do locador igual ao do locatário, o do empreiteiro igual ao do dono da obra e assim por diante (THEODORO JÚNIOR, 2004, p. 46).

Visando a regulamentar de forma expressa a utilização do contrato, quebrando a sua finalidade exclusivamente monetária, o artigo 421 do Código Civil brasileiro de 2002 recepcionou o princípio da função social do contrato. Dispõe essa norma: "A liberdade de contratar será exercida em razão e nos limites da função social do contrato."

Portanto, surge como resposta à pergunta, a função social do contrato como meio protetivo ao interesse social e à coletividade difusa em meio ao mundo empresarial que se encontra imerso nesta sociedade de consumo. 
A função social, antes mesmo da previsão expressa do Código Civil de 2002, já era um princípio do ordenamento jurídico brasileiro, decorrente da valorização social da livre iniciativa e da função social da propriedade. O princípio, além de gerar benefício ao titular da propriedade, deve gerar, ainda, retorno à sociedade.

Em verdade, a função social do contrato prevê uma limitação à liberdade contratual, exigindo que esta seja exercida com observância de suas consequências públicas, sendo certo que grande parte dos contratos afeta a coletividade.

A função social do contrato consiste em abordar a liberdade contratual em seus reflexos sobre a sociedade (terceiros) e não apenas no campo das relações entre as partes que o estipulam (contratantes) (THEODORO JÚNIOR, 2004, p. 31).

Dessa forma, não há mais espaço para o frio calculismo lucrativo do modelo contratual capitalista, devendo os contratos empresariais, elaborados sob a orientação social do Estado Democrático de Direito, privilegiar a justiça social. Ainda, a função social do contrato é uma projeção da função social da propriedade.

Sendo a função social do contrato uma projeção da função social da propriedade, de que verdadeiramente se origina, é bom acentuar que a propriedade, hoje, vem explícita na Constituição como direito e garantia individual, por isso seu acesso, pelo contrato - e aí a histórica ligação entre ambos os institutos - deve ser democratizado (art. $5^{\circ}, \mathrm{XXXIII).} \mathrm{Por} \mathrm{outra,} \mathrm{tal} \mathrm{se} \mathrm{dá} \mathrm{na} \mathrm{exata} \mathrm{medida} \mathrm{em} \mathrm{que} \mathrm{o} \mathrm{contrato}$ funcionalizado instrumentaliza a aquisição dos bens vitais à pessoa humana, mas, da mesma forma, marcado pela necessidade de atendimento não só do interesse da parte como também ao atendimento de interesses e valores sociais. E tais valores sociais encontram-se, primeiro, na própria Constituição (GODOY, 2004, p. 122).

Concepção inovadora acerca da função social vem sendo tratada, com propriedade, por Luciano Timm (2008, p. 85-86) ao abordar os diálogos entre direito e economia.

A principal função social do direito contratual é possibilitar a ocorrência dos contratos, o fluxo de trocas no mercado, a alocação de riscos pelos agentes econômicos e seu comprometimento em ações futuras até que seja alcançada a situação mais eficiente, isto é, quando ambas as partes recebem os benefícios econômicos da barganha e distribuem o saldo positivo resultante da transação. 
A abordagem singular trazida por Timm avança para indicar a busca pelo equilíbrio nas relações negociais, destacando a importância para um ganho de benefícios por ambas as partes.

Rita de Cássia Resquetti Tarifa et all (2005, p. 158), enfatizam: "No campo da função social, tem-se tido como diretriz de consideração da causa a função econômico-social objetivada no próprio ato do negócio."

Neste contexto de transformações do contrato, orientado pela função social, destaca-se a questão: até que ponto esta orientação é meramente principiológica ou em que medida deve o Poder Judiciário limitar a liberdade contratual em virtude do princípio da função social do contrato?

Se o contrato não cumpre sua função social, isto é, se revela ofensivo a direitos de terceiros ou agride interesses de ordem pública caros ao consenso da sociedade e se mostra incompatível com comandos cogentes do direito positivo, ao juiz compete aplicar-lhe a sanção da nulidade ou da ineficácia, conforme o caso. Se isto não for suficiente para evitar o prejuízo de terceiros, a tutela aos prejudicados consistirá em impor aos infratores a responsabilidade civil, sujeitando-os ao ressarcimento próprio dos atos ilícitos (THEODORO JÚNIOR, 2004, p. 145-146).

Então, caso o contrato se desvie de sua função social, deverá incidir uma sanção jurídica, pois a realização de um acordo de vontades sem observar esse princípio atinge o campo da ilicitude.

Resta claro, portanto, que a função social do contrato é princípio fundamental do novo modelo contratual, devendo ser respeitado e exigido pelas instâncias judiciais, não podendo as partes que contratam ignorá-lo em prol da atividade econômica. Contudo, surge uma questão importante: como equilibrar a função social e a função econômica dos contratos? Ou seja, como auferir lucros e cumprir a função principal da atividade empresária sem, contudo, deixar de promover o benefício social?

A resposta é trazida brilhantemente por Professor Luciano Timm (2010, p. 5):

Através da análise econômica do direito, podemos promover sim, uma justiça social, de maneira que serão analisados quais os impactos das decisões judiciais numa economia de mercado. Fica evidente que o dialogo entre o Direito e a Economia precisa se tornar cada vez mais frequente, afinal é necessário para que o desenvolvimento econômico do nosso país seja permito. Desenvolvimento este, que irá gerar um Estado Social digno e competente para atender a coletividade, pois atender a coletividade, promover a justiça social não é somente 
revisar o contrato de determinado cidadão, sem que seja analisada a consequência da decisão para num ambiente de mercado, aonde todos são partes.

A solução está em contrabalançar o interesse econômico e a tutela jurídica de conformidade com a interpretação jurisprudencial atual, ou seja, proteger os interesses individuais contratuais, respeitando os pressupostos de foro social. Nesse sentido, deve ser observada decisão do Tribunal de Justiça do Rio Grande do Sul (TJRS):

SISTEMA FINANCEIRO DA HABITAÇÃO. AÇÃO DE REVISÃO CONTRATUAL. TABELA PRICE. JUROS COMPENSATÓRIOS. INDEXADOR. POUPANÇA. PERCENTUAL SOBRE RENDA. REPETIÇÃO DO INDÉBITO. FUNÇÃO SOCIAL DO CONTRATO. SEGURO. MULTA. Possibilidade de revisão e adequação do contrato, estabelecendo o equilíbrio nas relações negociais existentes entre as partes, dentro daqueles parâmetros que confere o Estado de Direito e a função precípua do Poder Judiciário. APELAÇÃO PARCIALMENTE PROVIDA. (Apelação Civil n ${ }^{\circ}$ 70009794090, $9^{\mathrm{a}}$ Câmara Cível, TJRS, 13/04/2005)

No caso citado, o Tribunal de Justiça do Rio Grande do Sul alterou o contrato de financiamento habitacional com o objetivo de gerar equilíbrio entre as partes. O tribunal decidiu admitir o reajuste pelo índice de correção da poupança com o cômputo apenas da TR sem os juros, afastando a Tabela Price, que era o indexador contratado para corrigir os juros, pois essa, no entendimento do magistrado, era abusiva, porque geraria a cobrança de juros sobre juros que, conforme entendimento do tribunal, não seria legal.

APELAÇÃO CÍVEL. REPRESENTAÇÃO COMERCIAL. PRETENDIDA ANULAÇÃO DA RESCISÃO CONTRATUAL E RESPECTIVA QUITAÇÃO, COM FUNDAMENTO NO ALEGADO, MAS NÃO PROVADO, ESTADO DE PERIGO, INSTITUÍDO PELO ART. 156 DO CCB ATUAL. FUNÇÃO SOCIAL DO CONTRATO. ÔNUS DA PROVA. A função social do contrato tem por objetivo evitar a imposição de cláusulas onerosas e danosas aos contratantes economicamente mais fracos. Os efeitos legais da função social do contrato são a aplicação da cláusula rebus sic stantibus, a excessiva onerosidade superveniente e a modificação ou anulação do contrato, em decorrência do aproveitamento de um estado de necessidade comum ao estado de perigo (art. 156, Código Civil), ou captando a inexperiência do outro para a obtenção de vantagem exagerada como ocorre na lesão (art. 157, Código Civil), desde que provado. 
[...]. NEGADO PROVIMENTO AO RECURSO. UNÂNIME. (Apelação Cível n 70.001.602.091, Décima Quinta Câmara Cível, TJRS, julgada em 08.06.05)

Com a análise jurisprudencial supra, observa-se que a função social do contrato não é meramente uma abstração jurídica ou princípio preterido pelos tribunais, e que possui, sim, real aplicabilidade prática, efetiva e pontual, podendo invalidar ou alterar contratos que deixarem de cumpri-la. O julgado do TJRS reconhece como efeito legal da função social a aplicação da cláusula rebus sic stantibus frente à onerosidade excessiva superveniente e a modificação ou anulação do contrato em decorrência de um estado de necessidade comum a um estado de perigo. A decisão exarada no acórdão supra amplia a aplicação do princípio da função social em relação aos seus efeitos legais, reconhecendo o alcance do princípio não só em relação ao plano da eficácia, mas, também, ao plano da validade ao admitir o aproveitamento de um estado de necessidade comum a um estado de perigo, previstos no capítulo dos Defeitos do Negócio Jurídico, arts. 156 e 157 , respectivamente.

Contratar sem desrespeitar a sociedade, por si só, já é função social, na medida em que não gera dano e negatividades à sociedade. Portanto, se o contrato ainda produz externalidades positivas como o pagamento de tributos, a seguridade social, o benefício à sociedade, dentre outros, este passa a ser um modelo contratual ideal, em que há o equilíbrio de função social e econômica, modelo este chave para a empresa moderna socialmente funcionalizada, como a seguir será abordado.

\subsection{A FUNÇÃO SOCIAL DA EMPRESA}

Conforme já exposto, exercer uma função social significa atingir um objetivo útil, não apenas para os sujeitos diretamente envolvidos, mas também para a sociedade. Ademais, "considerando a função econômica da empresa como fonte geradora de riquezas, impostos, emprego e lucro, não é certo dizer que, só por funcionar, a empresa cumpre sua função social" (MAGALHÃES, 2007, p. $345)$.

A empresa atual tem extrema importância social, gerando reflexos imediatos na coletividade. Ela concentra a prestação de serviços, fornecimento de bens, geração de empregos, coleta dinheiro para o Estado por meio dos impostos, bem como contribui para a constante interligação de mercado e sociedade.

Dessa forma, não se pode mais aceitar uma visão meramente capitalista, externa à função social da empresa. Sobre a importância da empresa, Ana Frazão de Azevedo Lopes (2006, p. 119) sugere que: 
A empresa é vista como instituição cuja importância transcende à esfera econômica e passa a abarcar interesses sociais dos mais relevantes, como a própria sobrevivência e o bem-estar dos trabalhadores que para ela prestam seus serviços e dos demais cidadãos que dividem com ela o mesmo espaço social.

Não se pode mais pensar em um modelo empresarial meramente lucrativo, sem, contudo, observar a função social, e tutelar a sociedade e o homem dentro de sua atividade. Neste sentido:

A função social da empresa constitui o poder-dever de o empresário e os administradores da empresa harmonizarem as atividades da empresa, segundo os interesses da sociedade, mediante a obediência de determinados deveres, positivos e negativos (TOMASEVICIUS FILHO, 2003, p. 40).

Como já visto anteriormente, todas as sociedades empresárias são constituídas mediante um contrato, com exceção das sociedades por ações, e ainda, todas as relações entre o empresário e as pessoas ou entidades por ele afetadas ocorrem por meio de contratos.

Diante do aspecto contratual, bem como da relação de propriedade, ambos com normas positivadas que determinam o cumprimento de uma função social, percebe-se a inseparável ligação da empresa com o exercício de uma função social.

Nesse sentido, os contratos influenciam-se uns aos outros, bem como os direitos de propriedade. Então, se toda empresa parte da utilização da propriedade e de relações contratuais, pode-se afirmar que a função social da empresa decorre da função social da propriedade e da função social do contrato. É o que se extrai das ponderações de Ana Frazão de Azevedo Lopes (2006, p. 113-114), segundo as quais:

Decorrência necessária do reconhecimento da função social da propriedade e da função social do contrato foi a posterior discussão sobre a função social da empresa, como instituição cuja importância só aumentara no século XIX, não só no âmbito econômico, mas também no político e no social. Com efeito, a empresa assumira o papel de célula social catalisadora de aspirações, de anseios de prosperidade; de credora e, ao mesmo tempo, devedora da comunidade, o que evidenciava a sua natureza como comunidade de trabalho e de capital. Se toda atividade da empresa partia da utilização da propriedade e do contrato, é inequívoco que as transformações sobre estes institutos teriam reflexos diretos na própria empresa. Por outro lado, a sua crescente importância fez com que uma atenção especial fosse conferida 
aos bens de produção.

No mesmo sentido, as palavras de Sérgio de Abreu Ferreira (2009, p. 518): "A função social da empresa deve ser compreendida no feixe de interesses composto pela propriedade e pelos contratos (empresário, empregados e consumidores), que se entrelaçam a partir de sua razão estruturante."

Dessa forma, a empresa para cumprir sua função social não basta se manter ativa. Ela deve exercer suas atividades visando ao bem comum, sem praticar atos lesivos à coletividade.

A autonomia do empresário não é mais um completo exercício do livre arbítrio. Os atos empresariais não devem apenas evitar fins contrários à sociedade, mas sim estar em conformidade com a razão pela qual a livre iniciativa foi garantida e reconhecida: busca da dignidade e da justiça social. Para Ana Frazão de Azevedo Lopes (2006, p. 232), "a autonomia traz em si a necessária compatibilização entre a liberdade e a igualdade a partir de um critério de justiça".

O exercício da empresa, atuado de acordo com o máximo de coordenação possível, isto é de programação, evitaria, v.g., em termos de "segurança", comprometer a saúde dos homens, o ambiente e, em geral, o equilíbrio ecológico (tome-se, como exemplo, o tema da economia de energia e as proibições contra as poluições e as sofisticações). Mais marcada deve ser, também no intérprete, a consciência de que o crescimento econômico e o consequente bem-estar (benessere) quando não preservam a qualidade de vida, ou seja, a "liberdade" e a "dignidade humana", não são progresso e desenvolvimento social e constitucionalmente valoráveis, mas se traduzem, antes ou depois, em um mal-estar para todos (PERLINGIERI, 2007, p. 228).

Como visto então, a empresa não pode agir de forma egoística, unicamente focada em obter lucros, sem, contudo, observar a sua condição de elemento social, mas mantendo o equilíbrio entre função social e econômica, como visto anteriormente. Portanto, não se pode esquecer a função primordial da empresa, o lucro. Posto isso, tais características não podem ser desconsideradas a pretexto de cumprir, unicamente, uma atividade social. É neste sentido a observação de Rodrigo Almeida Magalhães (2007, p. 343), que sustenta:

Logo, a função social não tira a liberdade do indivíduo de agir de acordo com os próprios interesses, mas terá deveres com a sociedade determinados pelos princípios e normas jurídicas, positivadas ou não, limitando a autonomia privada em razão do bem comum. Diante do exposto, a sociedade só poderá exigir das empresas a função social das atividades que constituem objeto dela, ou seja, ligado à sua ativi- 
dade econômica exercida. Não é possível exigir, com fundamento na função social, deveres para os quais as empresas não foram criadas, porque senão só teria deveres e não direitos.

Uma sociedade empresária que não busca lucros não sobrevive e da sua ausência inevitavelmente acarreta prejuízos para a economia, a qual na atualidade é interligada. Neste sentido, a empresa deve ser exercida com a observância de sua função social, que é diferente de uma função de assistência social, conforme sugere Ana Frazão de Azevedo Lopes (2006, p. 126), a partir dos seguintes dizeres:

A funcionalização dos direitos não pode violar, pois, o âmbito em que a pessoa deve atuar como ser autônomo, campos em relação ao qual não é lícito converter o indivíduo em meio para os fins sociais.

Resta claro que a função social não destrói a liberdade do empresário e nem torna a empresa um simples meio para fins sociais, mesmo porque isso implica em violação à livre iniciativa. A função social não transforma uma sociedade empresária em órgão público assistencial. Sua finalidade é a de manter a responsabilidade social da empresa sem deixar de lado a busca do bem social enquanto exerce atividade econômica.

A racionalidade dos agentes, um dos postulados econômicos, que leva à procura da maximização de utilidades, e a eficiência alocativa, segundo essa visão, vão ao encontro da idéia de solidariedade e geração de bem-estar coletivo (SZTAJN, 2005, p. 76).

Ressalte-se que o princípio da função social da empresa impõe ao empresário o dever de exercer suas atividades com foco no benefício da coletividade e não meramente de não o exercer em prejuízo de outrem.

Sobre a função social da empresa, registra Eros Roberto Grau (2008, p. 238):

A função social da empresa - que suponho já estivesse embrionariamente postulada na contribuição de Courcelle-Seneuil, na afirmação da função social do comerciante, do proprietário e do capitalista aparece indiretamente no art. 42 da Constituição Italiana: "É livre a iniciativa econômica privada. Não pode, todavia, desenvolver-se em contraste com a utilidade social ou de modo a causar dano à segurança, à liberdade, à dignidade humana. A lei determina os programas e os meios de fiscalização destinados à direção e coordenação da atividade econômica, pública e privada, para fins sociais.” Nele resulta 
consagrada, em sua integralidade - o segundo inciso da disposição autorizando a imposição de limites negativos e o terceiro a imposição de limites positivos à iniciativa econômica - a função social da iniciativa econômica, portanto a função social da empresa. O princípio está também consagrado no direito positivo brasileiro. $\mathrm{O}$ art. 154 e o parágrafo único do art. 116 da lei 6.404/76 referem, de modo expresso, respectivamente, à função social da empresa e à função social da companhia.

No contexto do Estado Democrático de Direito brasileiro, interessa que o empresário atue sem causar prejuízos à coletividade e, ainda, contribuindo para a progressão social de todos, mais uma vez, pela via principal da ação da empresa, quais sejam os contratos empresariais, bem como pelas relações contratuais da empresa.

A empresa moderna, por meio de seus contratos, cumpre com o contrabalanço entre função social e econômica, com seu dever social, como um dos mecanismos de progressão e melhoria social, não agindo egoisticamente prejudicando os indivíduos da sociedade, nem tampouco esquecendo-se de sua finalidade principalmente lucrativa. Nota-se, portanto, uma íntima conexão entre os conceitos de função social da empresa e do contrato, já que ambos os conceitos se complementam, uma vez que a principal forma de cumprimento da função social da empresa se dá pelos contratos empresariais, socialmente funcionalizados.

\section{CONCLUSÃO}

As grandes transformações sociais observadas nos últimos séculos influenciaram o desenvolvimento das relações empresariais e negociais, implicando na extensa revisão do direito para atender a demanda crescente e complexa do trânsito jurídico realizado de forma intensa no campo empresarial.

Em decorrência das demandas advindas da intensidade do tráfego negocial, o direito privado passou por significativas mudanças expressas por meio de alterações trazidas pelo novo Código Civil e pela Constituição Federal.

Nessa esteira, a unificação parcial do Direito Civil e Direito Comercial em matéria empresarial e negocial uniformizou a disciplina contratual.

A função social da propriedade, como gênero, estendeu tal função para as demais espécies de propriedade, dentre elas, a propriedade empresarial, aplicando-se à propriedade dos bens de produção em alusão à função social da empresa.

A constitucionalização do negócio jurídico, rompendo com o paradigma pretérito definido pela liberdade e obrigatoriedade do contrato, promove o negócio jurídico a fim de atender as diretrizes constitucionais para tratar da dig- 
nidade da pessoa do contratante, igualdade material entre as partes, solidariedade negocial, afastando-se da tutela subjetiva da vontade e priorizando a tutela da confiança, consagrando de forma definitiva o princípio da boa-fé objetiva e da função social do contrato, sem preterir os princípios clássicos do contrato.

O contrato empresarial, instrumento de importância destacada para a atuação e realização das transações empresariais, representa força dinâmica, participando diretamente do desenvolvimento econômico.

A empresa, reconhecida pela importância de suas transações negociais, é considerada como feixe de relações contratuais, bem por isto, ampliando a dimensão negocial e sendo considerada como sujeito de direito econômico, responsável pelo trânsito negocial, assumindo na ordem econômica papel preponderante no que se refere à circulação de bens, produtos e serviços.

$\mathrm{O}$ contrato empresarial resgata a autonomia privada, antes limitada e criticada, como forma de reequilíbrio das relações negociais empresariais. Nesta perspectiva, os negócios jurídicos entre empresários são operacionalizados objetivando o fortalecimento dos princípios da livre iniciativa e da livre concorrência, interpretados de forma conjugada com o princípio da proteção da propriedade privada e o princípio da função social da propriedade.

Os contratos empresariais, na atualidade, caracterizam-se pela manutenção do fim lucrativo, da função econômica, do custo da transação, da confiança e da segurança conjugados com o fim social, a função social, o custo social, analisados através do chamado 'direito-custo'.

A função social decorre da funcionalização do direito e representa a preocupação e consideração para com os interesses da sociedade, sobrepondo-se aos interesses individuais, permitindo a valorização de situações jurídicas relacionadas aos interesses individuais e coletivos, mas com o afastamento do individualismo legado pelo modelo do estado liberal. Assim sendo, apresenta-se como condição de possibilidade para indicar e orientar a atuação do direito voltado para a consecução dos fins sociais.

O contrato empresarial tradicional é identificado por sua natureza e função econômica, caracterizado pela busca do lucro. A função social do contrato empresarial promove um deslocamento em seu eixo principal, atrelando a função econômica à função social e, deste modo, promovendo tais contratos para uma dimensão de busca de satisfação social, em que o lucro passa a ser considerado na dimensão econômico-social.

A função social do contrato empresarial comporta releituras e, considerando os diálogos entre direito e economia, pode-se inferir que nos contratos empresariais a principal função social é possibilitar a celebração de contratos, ampliando o fluxo negocial, dinamizando a compra e venda de bens e produtos e se comprometendo com as consequências decorrentes dos benefícios econômicos frente ao saldo positivo das transações empresariais. Sem dúvida, a função 
social atua, em certa medida, implementando a função econômica do contrato empresarial.

O princípio da função social tem atuação importante na hermenêutica negocial, sendo valorizado pelos tribunais pátrios que o consolidam nos contratos empresariais, decidindo, conforme a condição negocial, em favor da revisão do contrato, da rescisão do contrato, da anulação do contrato por violação ao princípio da função social.

Diante da funcionalização, mais que oportuna, se apresenta a função social da empresa igualmente caracterizada, de forma original, como fonte geradora de riquezas. Naturalmente, as sociedades empresariais atuais, redesignadas pela função social da empresa, fazem com que sua atuação transcenda os limites da esfera econômica para inserir-se no rol das sociabilidades nos quais o lucro se caracteriza por harmonizar as atividades da empresa, agora também de conformidade com os interesses da sociedade.

A atuação empresarial enfrenta análises críticas ponderadas entre uma linha de ataque e defesa. Se, por um lado, a empresa de modelo capitalista, que assim permanece, tem contra si o desgaste provocado pela atuação condenável da busca do ganho e do lucro como atuação exclusiva; por outro lado, a atuação empresarial marcada pela abertura trazida pelas transformações próprias da nova mentalidade empresarial conquista espaços no mercado mundializado cada vez maior em benefício do desenvolvimento da atividade econômica, conjugado com a atividade social.

O contrato empresarial funcionalizado traz para este contexto negocial as concepções humanizadas e referentes à necessidade da busca do equilíbrio em relação às obrigações materiais contratadas. Agregue-se a esta dimensão a invocação da solidariedade negocial, tendo por fundamento não só o interesse das partes vinculadas ao negócio, mas também a busca de instrumentos eficazes para a melhoria do bem-estar social no âmbito destes contratos que priorizavam, com exclusividade, os interesses da empresa.

O novo paradigma de contrato empresarial tem recebido total acolhimento por parte do Poder Judiciário que vem decidindo reiteradas vezes por coibir a conduta desleal, violadora do princípio da função social do contrato e do princípio da boa-fé objetiva. Cabe frisar que as grandes empresas com atuação principalmente envolvendo contratos de seguro em geral, direitos do consumidor, dentre outros, têm obtido ganho de causa com base e fundamento nesta visão socializada do contrato empresarial.

Função social e responsabilidade social são conquistas que decorrem desta fase de sociabilidade do direito, da empresa, dos contratos, pois que atendem aos próprios anseios de uma sociedade que espera e acredita na diminuição das distâncias petrificadas entre o mais forte e o mais fraco.

A empresa moderna equilibra função econômica e função social ao 
mesmo tempo em que trata do lucro financeiro com a mesma atenção dedicada ao lucro social. Nos contratos individuais ou nos contratos coletivos, como nas relações de consumo, os princípios da solidariedade, da boa-fé objetiva, da função social, recebem igual atenção e tratamento. Nos contratos celebrados entre as próprias empresas e, portanto, onde a função econômica assume relevo ainda maior, são dispensadas iguais atenção aos princípios nomeados.

A iniciativa privada, reorganizada de conformidade com os parâmetros sócio-econômico, ético e jurídico, atua de forma respeitável em espaço próprio, e em conjunto com a atuação estatal de forma harmoniosa, produzindo resultados positivos em relação à atuação de ambas. Assim sendo, a empresa que atende às necessidades econômicas e sociais se estabelece em um mercado em que circulam fins econômicos em convergência com os fins sociais, a responsabilidade social, fortalecendo as redes de contratos, desenvolvendo ações sociais por meio de atuação concreta respaldada em princípios, contribuindo para transformação e o crescimento econômico e social.

\section{REFERÊNCIAS}

BRASIL. Tribunal de Justiça do Rio Grande do Sul. Apelação Civil no 70009794090, 9a Câmara Cível, 13 abr. 2005.

. Tribunal de Justiça do Rio Grande do Sul. Apelação Cível no

70.001.602.091, Décima Quinta Câmara Cível, julgada em 08 jun. 2005.

FERREIRA, Sérgio de Abreu. O direito da empresa em crise, 2009.

Disponível em: <http://re.granbery.edu.br/artigos/MTI3.pdf>. Acesso em: 03 set. 2014.

GODOY, Arnaldo S. M. Globalização, Neoliberalismo e o direito no Brasil. Londrina: Humanidades, 2004.

GRAU, Eros Roberto. A ordem econômica na Constituição de 1988. 13. ed. São Paulo: Malheiros, 2008.

LOPES, Ana Frazão de Azevedo Lopes. Empresa e propriedade função social e abuso de poder econômico. São Paulo: Quartier Latin, 2006.

MAGALHÃES, Rodrigo Almeida. A autonomia privada e a função social da empresa. In: FIUZA, César; NAVES, Bruno Torquato de Oliveira; SÁ, Maria de Fátima Freire de (Coord.). Direito civil: atualidades II. Da autonomia privada nas situações jurídicas patrimoniais e existenciais. Belo Horizonte: Del 
Rey, 2007.

PERLINGIERI, Pietro. Perfis do direito civil: introdução ao direito civil constitucional. Tradução Maria Cristina De Cicco. Rio de Janeiro: Renovar, 2007.

SZTAJN, Raquel. Teoria jurídica da empresa: atividade empresária e mercados. São Paulo: Atlas, 2004.

TARIFA, Rita de Cássia Resquetti et al. A doutrina da causa e a relação negocial. p. 113-167. In: CATALAN, Marcos Jorge. Negócio jurídico: aspectos controvertidos à luz do novo código civil. São Paulo: Mundo Jurídico, 2005.

THEODORO JÚNIOR, Humberto. O contrato e sua função social. 2. ed. Rio de Janeiro: Forense, 2004.

TIMM, Luciano Benetti. Direito, economia e a função social do contrato: em busca dos verdadeiros interesses coletivos protegíveis no mercado de crédito. Disponível em: <http://www.gv.br/biblioteca/pe/SP000515251.pdf > Acesso em: 22 ago. 2014.

. Direito \& economia. 2. ed. Porto Alegre: Livraria do Advogado, 2008.

TOMASCEVICIUS FILHO, Eduardo. A Função social da empresa. Revista dos Tribunais, São Paulo, n. 92, p. 33-50, abr. 2003.

\section{THE SOCIAL ROLE OF BUSINESS AGREEMENTS}

ABSTRACT: The main transformations of private law have led to the unification of the legal subject of legal and corporate businesses, with the constitutional recognition of the importance of the private sector based on economic order principles. The importance of business agreements and contemporary companies follows the negotiating dynamics in a globalized economy. The previous model of business agreements, which relates exclusively to profit shifts towards new profile, aiming to harmonize the economic role with the legal certainty and predictability in relation to cost-effectiveness as supporting factors. The social role of business agreements promotes the review of the economic role of covenants to meet both economic and social interests, by promoting the circulation of wealth and property, but limited to obtaining profit as its sole purpose. The current company, considered as the beacon of contractual relations and subject of economic law, keeps the pursuit of profit as a natural end; however, in order to correct 
distortions for the promotion of business activity, covering economic, legal and social interests. The social responsibility of companies is stated in this context in order to meet the social effect that their actions can produce beyond the generation of wealth. Contemporary companies reorganize themselves to contemplate the economic and social purposes, exercising the business activity supported on principles and values, contributing to the economic and social development and growth.

KEYWORDS: Business Agreement; Contemporary company; Social Role.

\section{LA FUNCIÓN SOCIAL DEL CONTRATO EMPRESARIAL}

RESUMEN: Las principales transformaciones del derecho privado provocaran la unificación de la disciplina jurídica, de los negocios jurídicos y de la empresa, con el reconocimiento constitucional de la importancia de la iniciativa privada con fundamento en los principios de orden económica. La importancia de los contratos empresariales y de la empresa contemporánea sigue la dinámica de negociación en una economía globalizada. El modelo exitoso de contrato empresarial, que se destina exclusivamente a la ganancia, se dirige para nuevo perfil, objetivando armonizar la función económica, la seguridad y la previsibilidad jurídica en relación al costo beneficio como factores de sustentación. La función social del contrato empresarial promueve la revisión de la función económica de los pactos para atender los intereses económicos y los sociales, promoviendo la circulación de riquezas y bienes, pero limitando la obtención del lucro como fin exclusivo. La empresa actual, considerada como conjunto de relaciones contractuales y sujeto de derecho económico, mantiene la búsqueda de ganancia como fin natural, sin embargo, a fin de corregir distorsiones de forma a promover la actividad empresarial, contemplando intereses económicos, jurídicos y sociales. La responsabilidad social de la empresa se asegura, en este contexto, para atender al efecto social que sus actos puedan producir para además de la generación de riquezas. La empresa contemporánea se reorganiza para contemplar fines económicos y fines sociales, ejerciendo la actividad empresarial respaldada en principios y valores, contribuyendo para el desarrollo y el crecimiento económico y social.

PALABRAS CLAVE: Contrato Empresarial; Empresa Contemporánea; Función Social. 